\title{
Comunicação
}

[Communication]

\section{Perfil de sensibilidade e multirresistência em linhagens de Escherichia coli isoladas de infecção do trato urinário, de piometra e de fezes de cães}

\author{
[Sensitivity profile and multiresistance in Escherichia coli strains isolated from urinary tract infection, \\ pyometra and feces of dogs]

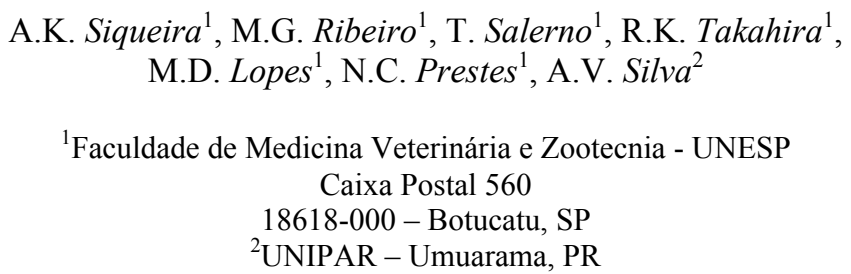

Escherichia coli (E. coli) é considerada o principal microrganismo na casuística de infecções do trato urinário (ITU) no homem e em animais. À semelhança das ITU, E. coli é comumente isolada na piometra em cães, ocorrendo como o único agente ao redor de 59 a 96\% dos casos (Nelson e Couto, 2003; Greene, 2006).

Russo e Johnson (2000) propuseram a utilização do acrônimo extra-intestinal pathogenic E. coli (ExPEC) para denominação de linhagens de $E$. coli não diarreiogênicas, associadas às infecções extra-intestinais. Dependendo do sistema ou do órgão acometidos, essas linhagens também podem ser denominadas uropathogenic E. coli (UPEC), meningits - associated E. coli (MNEC) e avian pathogenic E. coli (APEC) (Russo e Johnson, 2000; Kaper et al., 2004). Estudos têm apontado que as linhagens de $E$. coli isoladas de ITU e piometra são bioquimicamente e geneticamente semelhantes (Fransson e Ragle, 2003). No entanto, ExPEC são filogeneticamente e epidemiologicamente distintas das bactérias comensais e patogênicas dos intestinos (Russo e Johnson, 2000).

A presença de fatores de virulência é fundamental para que os microrganismos possam se estabelecer no sistema gênito-urinário, especialmente enterobactérias como $E$. coli
(Greene, 2006; Sousa, 2006). Determinadas linhagens apresentam resistência aos antimicrobianos por produzirem enzimas, mutações e seleção genética ou por possuírem em seu DNA fator de resistência denominado fator R (Nelson e Couto, 2003).

O objetivo deste estudo foi avaliar o perfil de sensibilidade e a ocorrência de multirresistência em linhagens de E. coli isoladas de ITU, piometra e fezes de cães sem sintomas entéricos.

Foram utilizadas 158 linhagens de E. coli isoladas de 52 casos de ITU, 51 de piometra e 55 das fezes de cães sem sintomas entéricos. Todas as linhagens foram submetidas ao método de difusão com discos em ágar (Bauer et al., 1966) utilizando-se: ampicilina $(10 \mu \mathrm{g})$, cefalexina $(30 \mu \mathrm{g})$, ceftiofur $(30 \mu \mathrm{g})$, ciprofloxacina $(5 \mu \mathrm{g})$, enrofloxacina $(5 \mu \mathrm{g})$, florfenicol $(30 \mu \mathrm{g})$, gentamicina $(10 \mu \mathrm{g})$, norfloxacina $(10 \mu \mathrm{g})$ e sulfametoxazol com trimetoprim $(25 \mu \mathrm{g})$. Foram consideradas multirresistentes as linhagens que apresentaram resistência a três ou mais antimicrobianos. Como controle do teste de difusão com discos foram utilizadas as cepas de Escherichia coli ATCC FVL2, FVL8, FVL16, FV35, J96, ORN115 e O157H7 cedidas pelo Prof. Dr. Domingos da Silva Leite, Laboratório de Antígenos Bacterianos II, Unicamp, Campinas, SP. 
Os maiores índices de sensibilidade das linhagens de E. coli isoladas de ITU foram observados para gentamicina, ciprofloxacina e norfloxacina. Para piometra, a ordem de sensibilidade foi: norfloxacina, ciprofloxacina e enrofloxacina. Para o grupo-controle (fezes), a efetividade foi observada com o uso de ciprofloxacina, norfloxacina e florfenicol. O maior índice de resistência das linhagens foi observado com o uso de sulfametoxazole/trimetoprim em $64,7 \%$ das linhagens isoladas de ITU, 73,1\% de piometra e $61,8 \%$ das fezes (Tab. 1). A ocorrência de E. coli resistente a pelo menos três antimicrobianos foi observada em $24(47,1 \%)$ linhagens isoladas de ITU, sete $(13,5 \%)$ de piometra e quatro $(7,3 \%)$ do grupo-controle. Resistência a cinco ou mais drogas foi constatada em $17 \quad(33,3 \%)$ das linhagens isoladas de ITU, uma $(1,9 \%)$ de piometra e três $(5,5 \%)$ de fezes (Tab. 2). A freqüência de linhagens resistentes a três ou mais e a cinco ou mais antimicrobianos foi comparada entre os grupos pelo teste de Kruskall-Wallis. Todos os cálculos foram realizados utilizando-se o programa Epilnfo 6 (Centers for Disease Control, Atlanta), considerando um nível de significância $\alpha=0,05$.

Tabela 1. Sensibilidade microbiana em linhagens de Escherichia coli isoladas de infecções do trato urinário, (G1), piometra (G2) e fezes de cães sem sintomas entéricos (controle)

\begin{tabular}{|c|c|c|c|c|c|c|c|c|c|}
\hline \multirow{3}{*}{ Antimicrobiano } & \multicolumn{3}{|c|}{ G1 } & \multicolumn{3}{|c|}{ G2 } & \multicolumn{3}{|c|}{ Controle } \\
\hline & $\mathrm{s}$ & ps & $\mathrm{r}$ & $\mathrm{s}$ & ps & $\mathrm{r}$ & $\mathrm{s}$ & ps & $\mathrm{r}$ \\
\hline & \multicolumn{3}{|c|}{ n $(\%)$} & \multicolumn{3}{|c|}{ n (\%) } & \multicolumn{3}{|c|}{ n (\%) } \\
\hline Ampicilina & $\begin{array}{c}16 \\
(31,7)\end{array}$ & $\begin{array}{c}6 \\
(11,7)\end{array}$ & $\begin{array}{c}29 \\
(56,8)\end{array}$ & $\begin{array}{c}32 \\
(61,5)\end{array}$ & $\begin{array}{c}5 \\
(9,6)\end{array}$ & $\begin{array}{c}15 \\
(28,8)\end{array}$ & $\begin{array}{c}49 \\
(89,1)\end{array}$ & $\begin{array}{c}0 \\
(-)\end{array}$ & $\begin{array}{c}6 \\
(10,9)\end{array}$ \\
\hline Cefalexina & $\begin{array}{c}24 \\
(47,0)\end{array}$ & $\begin{array}{c}8 \\
(15,7)\end{array}$ & $\begin{array}{c}34 \\
(66,7)\end{array}$ & $\begin{array}{c}39 \\
(75,0)\end{array}$ & $\begin{array}{c}8 \\
(15,4)\end{array}$ & $\begin{array}{c}5 \\
(9,6)\end{array}$ & $\begin{array}{c}49 \\
(89,1)\end{array}$ & $\begin{array}{c}3 \\
(5,4)\end{array}$ & $\begin{array}{c}3 \\
(5,4)\end{array}$ \\
\hline Ceftiofur & $\begin{array}{c}30 \\
(58,8)\end{array}$ & $\begin{array}{c}16 \\
(31,4)\end{array}$ & $\begin{array}{c}5 \\
(9,8)\end{array}$ & $\begin{array}{c}37 \\
(71,1)\end{array}$ & $\begin{array}{c}12 \\
(23,1)\end{array}$ & $\begin{array}{c}3 \\
(5,7)\end{array}$ & $\begin{array}{c}49 \\
(89,1)\end{array}$ & $\begin{array}{c}4 \\
(7,2)\end{array}$ & $\begin{array}{c}2 \\
(3,6)\end{array}$ \\
\hline Ciprofloxacina & $\begin{array}{c}32 \\
(62,7)\end{array}$ & $\begin{array}{c}3 \\
(5,9)\end{array}$ & $\begin{array}{c}16 \\
(31,4)\end{array}$ & $\begin{array}{c}47 \\
(90,4)\end{array}$ & $\begin{array}{c}3 \\
(5,7)\end{array}$ & $\begin{array}{c}2 \\
(3,8)\end{array}$ & $\begin{array}{c}51 \\
(92,7)\end{array}$ & $\begin{array}{c}1 \\
(1,8)\end{array}$ & $\begin{array}{c}3 \\
(5,4)\end{array}$ \\
\hline Enrofloxacina & $\begin{array}{c}31 \\
(60,8)\end{array}$ & $\begin{array}{c}4 \\
(7,8)\end{array}$ & $\begin{array}{c}16 \\
(31,4)\end{array}$ & $\begin{array}{c}47 \\
(90,4)\end{array}$ & $\begin{array}{c}4 \\
(7,7)\end{array}$ & $\begin{array}{c}1 \\
(1,9)\end{array}$ & $\begin{array}{c}49 \\
(89.1)\end{array}$ & $\begin{array}{c}3 \\
(5,4)\end{array}$ & $\begin{array}{c}3 \\
(5,4)\end{array}$ \\
\hline Florfenicol & $\begin{array}{c}24 \\
(47,0)\end{array}$ & $\begin{array}{c}14 \\
(27,4)\end{array}$ & $\begin{array}{c}10 \\
(19,6)\end{array}$ & $\begin{array}{c}43 \\
(82,7)\end{array}$ & $\begin{array}{c}6 \\
(11,5)\end{array}$ & $\begin{array}{c}3 \\
(5,7)\end{array}$ & $\begin{array}{c}50 \\
(90,9)\end{array}$ & $\begin{array}{c}5 \\
(9,1)\end{array}$ & $\begin{array}{l}0 \\
(-)\end{array}$ \\
\hline Gentamicina & $\begin{array}{c}36 \\
(70,6)\end{array}$ & $\begin{array}{c}6 \\
(11,7)\end{array}$ & $\begin{array}{c}9 \\
(17,6)\end{array}$ & $\begin{array}{c}33 \\
(63,4)\end{array}$ & $\begin{array}{c}14 \\
(26,9)\end{array}$ & $\begin{array}{c}5 \\
(9,6)\end{array}$ & $\begin{array}{c}33 \\
(60,0)\end{array}$ & $\begin{array}{c}17 \\
(30,9)\end{array}$ & $\begin{array}{c}5 \\
(9,1)\end{array}$ \\
\hline Norfloxacina & $\begin{array}{c}32 \\
(62,7)\end{array}$ & $\begin{array}{c}3 \\
(5,9)\end{array}$ & $\begin{array}{c}16 \\
(31,4)\end{array}$ & $\begin{array}{c}51 \\
(98,1)\end{array}$ & $\begin{array}{l}0 \\
(-)\end{array}$ & $\begin{array}{c}1 \\
(1,9)\end{array}$ & $\begin{array}{c}51 \\
(92,7)\end{array}$ & $\begin{array}{c}1 \\
(1,8)\end{array}$ & $\begin{array}{c}3 \\
(5,4)\end{array}$ \\
\hline $\begin{array}{l}\text { Sulfametoxazol/ } \\
\text { Trimetoprim }\end{array}$ & $\begin{array}{c}18 \\
(35,3)\end{array}$ & $\begin{array}{c}0 \\
(-)\end{array}$ & $\begin{array}{c}33 \\
(64,7)\end{array}$ & $\begin{array}{c}14 \\
(26,9)\end{array}$ & $\begin{array}{c}0 \\
(-)\end{array}$ & $\begin{array}{c}38 \\
(73,1)\end{array}$ & $\begin{array}{c}21 \\
(38,2)\end{array}$ & $\begin{array}{c}0 \\
(-)\end{array}$ & $\begin{array}{c}34 \\
(61,8)\end{array}$ \\
\hline
\end{tabular}

ITU: infecção do trato urinário; s: sensível; ps: parcialmente sensível; r: resistente.

Tabela 2. Multirresistência in vitro de linhagens de Escherichia coli isoladas de infecções do trato urinário (G1), piometra (G2) e fezes de cães sem sintomas entéricos (controle)

\begin{tabular}{|c|c|c|c|c|}
\hline \multirow[t]{2}{*}{ Grupo } & \multicolumn{2}{|c|}{$\begin{array}{l}\text { Multirresistência a três ou mais } \\
\text { antimicrobianos }\end{array}$} & \multicolumn{2}{|c|}{$\begin{array}{l}\text { Multirresistência a cinco ou mais } \\
\text { antimicrobianos }\end{array}$} \\
\hline & $\operatorname{sim}$ & não & $\operatorname{sim}$ & não \\
\hline G1 $(n=51)$ & $24(47,1 \%) a$ & $27(52,9 \%)$ & $17(33,3 \%) \mathrm{a}$ & $34(66,7 \%)$ \\
\hline $\mathrm{G} 2(\mathrm{n}=52)$ & $7(13,5 \%) b$ & $45(86,5 \%)$ & $1(1,9 \%) b$ & $51(98,1 \%)$ \\
\hline Controle $(n=55)$ & $4(7,3 \%) c$ & $51(92,7 \%)$ & $3(5,5 \%) c$ & $52(94,5 \%)$ \\
\hline
\end{tabular}

Letras distintas na mesma coluna indicam diferenças significativas entre os grupos, pelo teste Kruskall-Wallis.

Yates (1996), ao estudar 30 cadelas com piometra, evidenciou alta sensibilidade de E. coli à enrofloxacina e gentamicina. Lara et al. (2008), ao testarem 15 linhagens de E. coli isoladas de cadelas com piometra, relataram $100 \%$ de resistência para ampicilina, cefalexina, ciprofloxacina, gentamicina e norfloxacina. Villarroel et al. (2002), na Venezuela, ao investigarem o perfil de sensibilidade de 538 linhagens de E. coli isoladas de cães com ITU, observaram boa sensibilidade dos agentes para gentamicina, fluorquinolonas e ampicilina. 
Sanchez et al. (2002), ao estudarem 21 linhagens de $E$. coli isoladas de urina de cães verificaram resistência para sulfonamidas, tetraciclinas, cefalosporinas e gentamicina. Von Sydow et al. (2006), ao avaliarem linhagens de E. coli isoladas de fezes de cães errantes, observaram $100 \%$ de sensibilidade para norfloxacina, $87,2 \%$ para enrofloxacina e $73,6 \%$ para gentamicina. Nesse mesmo estudo, foi observada alta efetividade com o uso de sulfametoxazole $(75,6 \%)$, droga altamente ineficaz nos 158 isolados estudados (Tab. 1).

A terapia das diferentes afecções bacterianas deveria fundamentar-se em testes de sensibilidade microbiana. Entretanto, a escolha dos antimicrobianos recai comumente na experiência profissional, no apelo comercial ou no custo de determinados produtos, aliada à dificuldade de acesso a laboratórios de microbiologia veterinária (Ribeiro et al., 2006). Cresce também, de forma preocupante, a indicação desses fármacos por pessoas não habilitadas que atuam em estabelecimentos comerciais do ramo de animais de companhia. Com efeito, o uso indevido e indiscriminado dos antimicrobianos (subdoses, superdoses, descontinuidade da terapia e "promotores de crescimento") pode aumentar a pressão seletiva para linhagens multirresistentes em cães e gatos.

A presença de linhagens de $E$. coli multirresistentes aos antimicrobianos em animais de companhia evidencia para os riscos em saúde pública, em virtude da provável transmissão de ExPEC dos animais para o homem, em face do estreito contato entre essas espécies. Maynard et al. (2004), ao investigarem ExPEC isoladas de diferentes espécies animais e do homem, encontraram $60 \%$ de resistência às sulfonamidas e acima de $50 \%$ para tetraciclinas e ampicilina. A multirresistência a três ou mais drogas foi encontrada em mais de $50 \%$ dos isolados, mostrando a similaridade de resistência entre linhagens isoladas de homens e outros animais.

Os estudos de vigilância bacteriológica são métodos de grande utilidade para se determinar as tendências da sensibilidade antimicrobiana das bactérias. Esses estudos são de validade temporal devido à capacidade das bactérias em desenvolverem mecanismos de resistência aos antimicrobianos. Essa realidade pressupõe a necessidade de estudos continuados de sensibilidade bacteriana, especialmente para $E$. coli, visando otimizar os protocolos terapêuticos e investigar a ocorrência de linhagens multirresistentes em virtude da possibilidade de transmissão cruzada entre homens e outros animais.

Palavras-chave: cão, E. coli, sensibilidade antimicrobiana, infecção do trato urinário, piometra

\begin{abstract}
Susceptibility profile and multiple drug resistance in $158 \mathrm{E}$. coli strains isolated from urinary tract infection (UTI), pyometra, and feces of dogs were studied. Norfloxacin, ciprofloxacin, and enrofloxacin were the most-effective drugs (>60\%) for E. coli strains. High rates of resistance to antimicrobials were observed in $60 \%$ or more of the isolated strains using sulfametoxazole/trimetoprim. Multiple drug resistance for three or more antimicrobials was observed in two (47.1\%) strains isolated from UTI, seven (13.5\%) from pyometra, and four (7.3\%) from feces. From these, 17 (33.3\%), one (1.9\%), and three (5.5\%), respectively, showed multiple resistance to five or more drugs.
\end{abstract}

Keywords: dog, E. coli, antimicrobial susceptibility, urinary tract infection, pyometra

\section{REFERÊNCIAS BIBLIOGRÁFICAS}

BAUER, A.W.; KIRBY, W.M.M.; SHERRIS, J.C. et al. Antibiotic susceptibility testing by a standardized single disk method. Am. J. Clin. Pathol., v.45, p.493-496, 1966.
FRANSSON, B.A.; RAGLE, C.A. Canine pyometra; an update on pathogenesis and treatment. Compendium, v.25, p.602-612, 2003.

GREENE, C.E. (Ed). Infectious diseases of the dog and cat. 3.ed. Canada: Saunders/Elsevier, 2006. 1387 p. 
KAPER, J.B.; NATARO, J.P.; MOBLEY, H.L.T. Pathogenic Escherichia coli. Nat. Rev., v.2, p.123-140, 2004.

LARA, V.M.; DONADELI, F.S.F.; CRUZ, A.B. et al. Multirresistência antimicrobiana em cepas de Escherichia coli isoladas de cadelas com piometra. Arq. Bras. Med. Vet. Zootec., v.60, p.1032-1034, 2008.

MAYNARD, C.; BEKAL, S.; SANSCHAGRIN, $F$. et al. Heterogeneity among virulence and antimicrobial resistance gene profiles of extraintestinal Escherichia coli isolates from animal and human origin. J. Clin. Microbiol., v.42, p.5444-5452, 2004.

NELSON, R.W.; COUTO, C.G. (Eds). Small animal internal medicine. 3.ed. St. Louis: Mosby, 2003. 1362p.

RIBEIRO, M.G.; COSTA, E.O.; LEITE, D.S. et al. Fatores de virulência em linhagens de Escherichia coli isoladas de mastite bovina. Arq. Bras. Med. Vet. Zootec., v.58, p.724-731, 2006.

RUSSO, T.A.; JOHNSON, J.R. Proposal for a new inclusive designation for extraintestinal pathogenic isolates of Escherichia coli: ExPEC. J. Infect. Dis., v.181, p.1753-1754, 2000.

SANCHEZ, S.; STEVENSON, M.A.A.; HUDSON, C.R. et al. Characterization of multidrug resistant Escherichia coli isolates associated with nosocomial infections in dogs. $J$. Clin. Microbiol., v.40, p.3586-3595, 2002.

SOUSA, C.P. The versatile strategies of Escherichia coli pathotypes: a mini review. J. Venom. Anim. Toxins Ind. Trop. Dis., v.12, p.363-373, 2006.

VILLARROEL, E.; NAVARRO, P.; RAMOS, R. et al. J. Escherichia coli identificadas em pacientes com infecciones urinarias: sensibilidade antimicrobiana. Rev. Soc. Venez. Microbiol., v.22, p.1-6, 2002.

VON SYDOW, A.C.M.D.G.; COOGAN, J.A.; MORENO, A.M. et al. Ocorrência de fatores de virulência em estirpes de Escherichia coli isoladas de fezes de cães errantes. Arq. Inst. Biol., v.73, p.401-407, 2006.

YATES, D.G. The antimicrobial sensitivity of bacteria isolated from 30 cases of pyometra in the bitch. Irish Vet. J., v.49, p.709-710, 1996. 